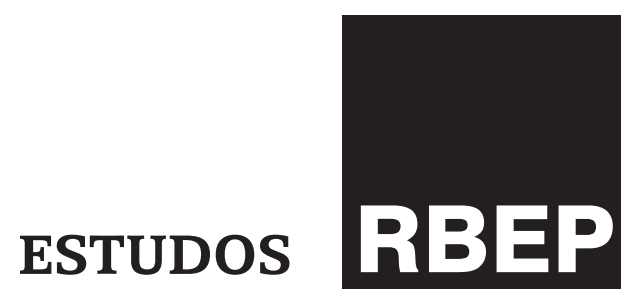

\title{
Ações afirmativas e educação superior no Brasil: um balanço crítico da produção
}

Jocélio Teles dos Santos

\section{Resumo}

Nos últimos anos, várias universidades públicas brasileiras instituíram um novo sistema de ingresso nos cursos de graduação. O sistema de cotas ou as ações afirmativas para estudantes negros, indígenas e oriundos do sistema público de ensino passou a ser um mecanismo de promoção de grupos e populações sub-representadas nas instituições de ensino superior. Este artigo analisa a introdução dessas ações tendo como foco a produção intelectual existente e os artigos publicados na Revista Brasileira de Estudos Pedagógicos (Rbep).

Palavras-chave: ações afirmativas; ensino superior; produção intelectual; Rbep. 


\section{Abstract \\ Affirmative action and higher education in Brazil: a critical balance on the production}

In recent years several brazilian public universities have instituted a new system to accessing undergraduate courses. The quota systems or affirmative action for black, native students, and those originating from the public school system became a mechanism of promotion for minority groups and populations with low representation in higher education. This article analyzes the introduction of these actions with a focus on the existing intellectual production and on the articles published by Revista Brasileira de Estudos Pedagógicos (Rbep).

Keywords: affirmative action; higher education; academic production; Rbep.

É recente a adoção de ações afirmativas no Brasil. Vistas como medidas para criar igualdade de oportunidades para grupos e populações socialmente excluídas, essas ações preveem um tratamento diferenciado na sua execução, objetivando uma maior inserção na educação, no sistema de saúde e no mercado de trabalho.

Como visto na literatura, a institucionalização das ações afirmativas ocorreu inicialmente na Índia: em um contexto marcado pela descolonização, um intelectual indiano, Bhimrao Ramji Ambedkar, foi o mentor de um sistema de cotas para as castas. A reserva de vagas foi aplicada aos intocáveis (dalits), minorias religiosas, tribos e castas que estavam entre os intocáveis e os djiva. O argumento foi que um "tratamento especial" deveria ser dado para os dalits e determinados grupos, já que não havia representação proporcional ao seu percentual na população da Índia. Os dalits eram 17\% da população e, em 1950, ocupavam 1\% dos postos graduados do país. Durante o processo de colonização esses grupos foram marginalizados nas estruturas de poder e no acesso à educação. Desde 1948, o sistema de cotas consta na Constituição do país e se estende aos órgãos legislativos, ao serviço público e às instituições de ensino. É diferenciado em relação a cada grupo, pois isso implica o seu reconhecimento oficial, não se tratando, portanto, de um direito individual.

A Malásia foi outro país asiático a adotar as ações afirmativas por meio da instituição de um sistema de cotas, em 1971, para os malaios e determinadas tribos, como os bamiputras ou bumiputeras; a lógica se assemelha ao sistema adotado na Índia. Essas populações se encontravam em uma desigualdade socioeconômica perante os chineses e indianos 
e necessitavam ser inseridas em posições de poder governamental e em instituições de ensino (Carvalho, 2006). A diferença é que havia reivindicações de caráter étnico em um contexto herdado do colonialismo. As medidas adotadas podem ser observadas como uma reivindicação da população nativa (os malaios); afinal, os chineses e indianos, que, respectivamente, correspondiam a 27\% e 8\% da população da Malásia, detinham uma maior participação na economia.

Se observado que as ações afirmativas são medidas, políticas e programas dirigidos a grupos e populações que estão vulneráveis a processos de discriminação, a lista de países, nos últimos anos, é a seguinte: Bósnia - em cargos políticos, as mulheres devem estar representadas com um percentual mínimo de 29\%; China - cotas para representação de minorias na Assembleia Nacional em Pequim e cotas para minorias ingressarem nas universidades; Macedônia-minorias, como os albaneses, têm cotas para acesso a universidades do Estado e no serviço público; Nova Zelândia - indivíduos descendentes de grupos polinésios e indígenas maori têm acesso preferencial para cursos universitários e bolsas; Indonésia programa de ação afirmativa dirigido para grupos nativos que migraram para o país; Eslováquia - ação afirmativa para indivíduos de grupos raciais ou minorias; Reino Unido - lei indica recrutamento igual de católicos e não católicos no serviço policial na Irlanda do Norte; África do Sul - cotas e metas para promover equidade no mercado de trabalho entre brancos e negros.

No Brasil essas ações têm se mostrado diferenciadas. No período da redemocratização houve uma grande demanda dos movimentos sociais para a inclusão de capítulos específicos para negros e indígenas e a inclusão de temáticas curriculares no ensino fundamental e médio; entretanto, no período dos anos 80-90 do século passado, as respostas institucionais foram asseguradas basicamente na Constituição Federal e nas Estaduais, com a elaboração de capítulos específicos. Somente no início do século 21 é que podemos perceber uma significativa mudança, pois várias instituições do ensino superior adotaram ações afirmativas para negros e indígenas, com ênfase no sistema de cotas. E desde 2003 há a obrigatoriedade das temáticas história e cultura do negro no Brasil nos currículos escolares, sancionada através da Lei $n^{\circ}$ 10.639/03, posteriormente alterada pela Lei n 11.645/08, que inclui no currículo oficial da rede de ensino a obrigatoriedade da temática "História e Cultura Afro-Brasileira e Indígena".

Nesse processo não se verifica um simples reconhecimento da contribuição das diferentes populações na formação cultural do País, algo que ocorreu desde os anos trinta, notadamente entre intelectuais, e que foi, desde os anos de 1960, incorporado até pelas instâncias governamentais. Trata-se, no último decênio, da reivindicação de direitos pelos movimentos sociais e elaboração de políticas públicas cujo foco é um discurso direcionado para a inclusão social. Nesse sentido, o sistema de cotas adotado para negros e indígenas nas universidades públicas pode ser incorporado no que se discute sobre multiculturalismo em contexto comparativo. Portanto, há que se verificar o que significou políticas educacionais diferenciadas em instituições que priorizavam até o último 
decênio um discurso universalista baseado no mérito para o ingresso no ensino superior.

\section{As ações afirmativas no Brasil: dilema secular}

Mesmo que outros países tenham estabelecido políticas de ação afirmativa, o debate na sociedade brasileira tendeu a priorizar os Estados Unidos como o locus da comparação para políticas que usam o critério racial como forma de promover equidade. Desde o século passado, os Estados Unidos são o país que serve para a comparação das desigualdades entre brancos e negros e adoção de políticas que possam diminuir as desigualdades raciais na sociedade brasileira, assim como no argumento contrário à adoção do sistema de cotas. As razões deste viés exclusivista americano na sociedade brasileira são de natureza histórica, sociológica e política.

No século 19, abolicionistas americanos e brasileiros priorizavam comparações entre os dois sistemas escravocratas (Azevedo, 1994). No século 20, vários estudos sociológicos e antropológicos desenvolvidos nos Estados Unidos e no Brasil priorizaram as diferenças raciais entre os dois modelos de sociedade (Hellwig, 1992; Telles, 2003; Guimarães, 1996). Os conceitos de raça e classe passaram a ser tomados como ferramentas analíticas para se compreender as razões da permanência das desigualdades, principalmente a partir da década de 40, e assim têm permanecido no debate acadêmico.

O uso recente da expressão ação afirmativa é resultado da influência estadunidense no debate das ações afirmativas direcionadas para a população negra. Apesar de o governo Franklin Roosevelt, no ano de 1941, e o governo Lyndon Johnson, em 1964, terem criado mecanismos legais para impedir a discriminação racial a negros na seleção e recrutamento para o serviço público, a expressão passou a ser um designativo de referência a ações voltadas para igualdade de oportunidades com a pressão do movimento dos direitos civis dos negros. No ano de 1961, o presidente John F. Kennedy instala a Comissão por Oportunidades Iguais de Emprego, e, a partir desse período, a expressão ação afirmativa passa a ser publicizada e popularizada.

Mesmo que nos últimos anos haja na sociedade brasileira uma influência de expressões e sentidos do que sejam as ações afirmativas na sociedade americana, é necessário verificar que, desde os anos 1940, estabeleceu-se a chamada "lei dos dois terços" para reserva de trabalhadores nacionais nas empresas brasileiras. Essa lei se aproximava ao artigo 354 da Consolidação das Leis do Trabalho (CLT), que, em 1943, determinava o percentual de dois terços de brasileiros empregados nas empresas como uma resposta à crescente imigração européia e asiática. O artigo 373-A já poderia ser considerado também uma medida de ação afirmativa, pois apontava a adoção de políticas direcionadas para corrigir as desigualdades de direitos entre homens e mulheres. Desse modo, o 
Brasil se aproxima muito mais das políticas particularistas da Malásia que as dos Estados Unidos.

Se comparadas com a adoção em outros países, as práticas educacionais multiculturalistas no ensino superior brasileiro têm características que se aproximam de outros contextos, pois são resultado de demandas de movimentos sociais, mas se distanciam de outras experiências, já que tendem a sobrevalorizar a adoção de algum sistema de cotas como resposta à inclusão de populações marginalizadas. Nesse sentido, as práticas educacionais multiculturais no ensino superior brasileiro são tanto transnacionais quanto se revestem de um forte nacionalismo na sua origem. E é possível afirmar que certa obsessão brasileira pela definição de políticas de cotas pode ter como gênese a década de 40, pois duas décadas depois, em pleno regime militar, apareceu a primeira proposta de reserva de vagas para negros na sociedade brasileira.

Em novembro de 1968, técnicos do Ministério do Trabalho e do Tribunal Superior do Trabalho, diante de denúncias de discriminação racial no mercado de trabalho, apontaram como solução a aprovação de lei que obrigasse as empresas privadas a manterem um percentual mínimo de empregados "de cor". Para os técnicos havia uma necessidade de regulação, com a adoção, pelas empresas, de percentuais diferenciados $-20 \%, 15 \%$ ou $10 \%$, a depender do ramo de atividades e do percentual da demanda (Santos, 2005). Coincidentemente, as duas propostas foram feitas em dois períodos ditatoriais: o do Estado Novo e o militar.

Essa proposta pode ser interpretada como uma adequação da política de ação afirmativa estadunidense para o acesso à educação e ao emprego às minorias étnicas/raciais ou sexuais, assim como uma atualização da "lei dos dois terços" dos anos quarenta. Essa iniciativa visava atenuar os constrangimentos daqueles que estavam sendo impedidos de serem contratados em razão da cor. As empresas usavam determinadas formas para não aceitarem empregados, como os formulários de admissão, o curriculum vitae, a filiação e a cor. A maioria delas exigia em anúncios classificados nos jornais que o candidato fosse branco. Mesmo reconhecendo a existência de preconceito racial no mercado de trabalho brasileiro, o pensamento oficial era de que a solução seria menos trabalhista e mais circunscrita à polícia e à justiça. Além das reações governamentais contrárias à proposta de cotas dos técnicos, havia a postura de escritores como Rachel de Queirós e da imprensa. Mesmo que distantes ideologicamente - o Jornal do Brasil, por exemplo, fazia oposição ao regime militar -, os discursos oficiais e não oficiais se aproximavam mais que se distanciavam (Santos, 2005).

Desde esse período até os dias atuais, a resistência à adoção de políticas de ações afirmativas no ensino superior, notadamente cotas para negros, tem se pautado nos seguintes argumentos: o do mérito ("a meritocracia individual estaria sendo negada na adoção do sistema de cotas"), o da definição de quem pode ser considerado negro ("o Brasil é um país mestiço") ou mesmo o jurídico ("a regulamentação de cotas é o reconhecimento da existência de discriminação do ponto de vista jurídico legal"). O primeiro argumento encontra similitude nos Estados Unidos. 
Como observou Walters (1995),

[os críticos acusavam] as cotas preferenciais de imporem negros e outras minorias [fossem] incluídos na força de trabalho de uma empresa em função de um método mecânico de preenchimento de metas proporcionais, e não por mérito ou qualificação. [Afirmavam] que o regime de ação afirmativa ignora as qualificações, especialmente os brancos qualificados, em favor de negros menos qualificados.

Essa acusação remontaria a uma decisão da Suprema Corte, em 1978, quando um candidato branco à Faculdade Davis de Medicina da Universidade da Califórnia apresentou a queixa de que se não fosse pelo programa de ação afirmativa ele teria sido admitido.

Na última década, a adoção de sistema de cotas em universidades públicas brasileiras provocou polêmicas que atualizam os debates seculares sobre políticas públicas direcionadas para a população negra. O que se manifesta é menos a crítica à adoção de ações afirmativas para diversos grupos e populações marginalizadas, mas, fundamentalmente, quando as ações afirmativas se reportam aos negros, principalmente no que concerne ao sistema de cotas. É importante frisar que, desde a promulgação da Constituição Brasileira, em 1988, existe uma Lei $\left(\mathrm{n}^{\circ} 8.112 / 90\right.$, art. $\left.5^{\circ}, \S 2^{\circ}\right)$ estabelecendo um sistema de cotas de até $20 \%$ para os portadores de necessidades especiais.

Também a Lei no 8.666/93, no art. 24, inciso XX (Lei das Licitações), determina a inexigibilidade de licitação para a contratação de entidades filantrópicas para portadores de necessidades especiais, assim como a Lei $n^{\circ}$ 8.213/91 estabelece um percentual na contratação de pessoas portadoras de necessidades especiais pelas empresas privadas, com limitação de até $5 \%$ para as que têm acima de mil empregados. Em relação ao mercado de trabalho, o art. $7^{\circ}$, inciso XX, da Constituição indica incentivos para empresas que contratem mulheres. Ainda em relação às ações afirmativas para mulheres, a Lei no 9.100/96, de autoria da deputada federal Martha Suplicy (PT-SP), reserva um percentual mínimo de 20\% das candidaturas nos partidos políticos para as mulheres.

Em relação ao contingente negro, é assegurada pela Constituição estadual da Bahia, desde 1989 (Capítulo XXIII - Do negro), a obrigatoriedade de inclusão de uma pessoa negra quando é "veiculada publicidade estadual com mais de duas pessoas" (art. 289). O governo do Distrito Federal assegura também, desde o ano de 1996, a representação proporcional de negros, brancos e índios na propaganda oficial. A partir do ano 2000, verificam-se ações governamentais, no âmbito federal, visando uma maior inserção de negros em espaços institucionais. Isso pode ser visto na adoção de cotas para negros (20\%, com a meta de 30\% a ser atingida em 2003) pelo Ministério do Desenvolvimento Agrário e no Instituto Nacional de Colonização e Reforma Agrária, na contratação de serviços terceirizados para negros (20\%), mulheres (20\%) e portadores de necessidades especiais (5\%) pelo Ministério da Justiça (2001) e na criação de 20 bolsas de estudos para negros que se candidatem 
à carreira de diplomata do Instituto Rio Branco, pelo Ministério das Relações Exteriores (2002).

Mesmo que já existisse a garantia constitucional para as ações afirmativas no País, assim como a indicação de reserva de vagas para determinados segmentos - portadores de necessidades especiais e mulheres - , o sistema jurídico só foi acionado quando da introdução do sistema de cotas para alunos egressos das escolas públicas, negros e indígenas em universidades públicas estaduais e federais. Os mandados de segurança impetrados apontam para a inconstitucionalidade das decisões normativas dos conselhos universitários e violação ao princípio da isonomia, do art. 208, V, da Carta Magna e do princípio da igualdade, presente no art. $5^{\circ}$. Os profissionais do direito se deparam com novas demandas sociais em que a política universalista passou a ser questionada através do princípio de que os desiguais devem ser tratados desigualmente.

\section{A produção intelectual sobre as ações afirmativas}

Nos últimos 11 anos cresceu a produção bibliográfica sobre a adoção de políticas de ações afirmativas no ensino superior. Um levantamento das teses, dissertações de mestrado e artigos publicados e disponibilizados pelas instituições de pós-graduação e revistas especializadas revela isso. Livros não foram incluídos, pois ainda é pequena a produção direcionada exclusivamente para a temática. ${ }^{1}$

A fonte é o site www.redeacaoafirmativa.ceao.ufba.br. O período corresponde ao início da adoção das ações afirmativas nas universidades estaduais do Rio de Janeiro - Universidade Estadual do Rio de Janeiro (Uerj) e Universidade Estadual do Norte Fluminense Darcy Ribeiro (Uenf) e finda em 2011, ano em que 104 instituições públicas de ensino (universidades estaduais e federais, institutos federais e centros universitários) haviam adotado políticas particularistas para o ingresso nas suas instituições. É provável que tenham escapado algumas teses, dissertações e artigos. De todo modo, acredito que a Tabela 1 é deveras representativa da produção temática no Brasil.

Tabela 1 - Produção Bibliográfica sobre a Adoção de Políticas Afirmativas no Ensino Superior Brasil 2001-2011

\begin{tabular}{|l|r|r|r|r|r|r|r|r|r|r|r|r|}
\hline \multicolumn{1}{|c|}{ Suportes } & 2001 & 2002 & 2003 & 2004 & 2005 & 2006 & 2007 & 2008 & 2009 & 2010 & 2011 & Total \\
\hline Teses & 1 & - & - & 3 & 1 & 1 & 2 & 4 & 4 & 3 & - & 19 \\
\hline Dissertações & - & - & 1 & 3 & 7 & 13 & 12 & 17 & 9 & 9 & - & 71 \\
\hline Artigos & 2 & 3 & 6 & 13 & 16 & 17 & 16 & 18 & 24 & 17 & 10 & 142 \\
\hline$\quad$ Total & $\mathbf{3}$ & $\mathbf{3}$ & $\mathbf{7}$ & $\mathbf{1 9}$ & $\mathbf{2 4}$ & $\mathbf{3 1}$ & $\mathbf{3 0}$ & $\mathbf{3 9}$ & $\mathbf{3 7}$ & $\mathbf{2 9}$ & $\mathbf{1 0}$ & $\mathbf{2 3 2}$ \\
\hline
\end{tabular}

Fonte: Disponível em: <www.redeacaoafirmativa.ceao.ufba.br>

\footnotetext{
$1 \mathrm{Um}$ dos poucos livros foi organizado por Brandão (2007).
} 
Observando a Tabela 1, vemos que, comparativamente, se destaca a publicação de artigos às teses de doutorado e dissertações de mestrado. Foram 19 teses, 71 dissertações de mestrado e 142 artigos. Há certa regularidade na produção das teses a partir do ano de 2004. O número oscila entre 1 e 4 . Uma variação no número de dissertações é significativa: o número passa de 3 em 2004 para 7 em 2005, 13 em 2006, e em 2008 alcança o total de 17 dissertações. Em dez anos de ações afirmativas na educação superior pública brasileira, tivemos uma média de 7,1 dissertações por ano produzidas na pós-graduação. E o número de artigos é o mais significativo: no período 2003-2010 verifica-se uma média de 15 artigos por ano, sendo o ano de 2009 o mais expressivo - 24 artigos -, o que demonstra uma demanda regular de pesquisadores em publicarem resultados de pesquisas realizadas tanto quanto se posicionarem em um campo bastante polarizado nas universidades e na sociedade brasileira. E dá para notar que algumas revistas não só publicaram, mas elegeram números temáticos sobre as ações afirmativas na educação superior. E aqui a Revista Brasileira de Estudos Pedagógicos (Rbep) se insere no campo dessa produção.

A temática das ações afirmativas na área da educação aparece na Rbep nos últimos dois anos: foram dez artigos, sendo oito no número temático publicado em set./dez. 2011. O primeiro artigo (Ferri et al., 2010) aparece no número 228; trata-se de uma reflexão sobre o Programa Universidade para Todos (ProUni). Criado por meio da Medida Provisória n 213, de 10 de setembro de 2004, e da Lei no 11.096, de 13 de janeiro de 2005, o ProUni é avaliado na Universidade do Vale do Itajaí. Na pesquisa, as autoras se propuseram a "analisar os índices de acesso, as condições de permanência e as experiências de aprendizagem dos alunos bolsistas do ProUni nos cursos de graduação da Universidade do Vale do Itajaí (Univali) no período 2006-2007". Lembrando o Plano Nacional de Educação (2000) e as metas de inclusão para minorias no ensino superior, penso que é pertinente refletir que se trata de uma ação do Estado amparado num discurso onde aparecem "conceitos de igualdade, universalização, democratização e justiça social". O universo analisado foram os dados dos estudantes que ingressaram nos "quatro semestres dos anos de 2006 e 2007, totalizando uma amostra de 1.000 estudantes investigados". E isso corresponde a 68,16\% do total de alunos.

Trazendo dados sobre origem geográfica, gênero, rendimento e estado civil, uma pergunta se apresenta: Por que não há dados na pesquisa sobre a cor dos sujeitos do ProUni na Univali? A universidade não teria coletado essa variável? O ProUni, como um programa governamental, teve apoio público de inúmeros pesquisadores, inclusive dos que se posicionaram contra as cotas raciais nas universidades públicas. Por outro lado, os argumentos contrários ao ProUni estavam mais direcionados para o que se indicava como deslocamento de recurso público para instituições privadas; vista como uma parceria do setor público com o setor privado, por conseguinte, o ProUni seria uma "grande negociata com o setor privado, isentando-o de impostos e contribuições" (Advir, 2005, p. 101). 
A ausência da cor dos sujeitos nessa pesquisa impede uma possível comparação com outros estudos que se debruçaram sobre a inclusão da população negra, alvo principal das posições contrárias ao sistema de cotas. Por certo é necessário refletir sobre a evasão, o levantamento de dados sobre o desempenho, e a reprovação, mas é cada vez mais necessário avaliar programas de inclusão no ensino superior em perspectiva comparativa, pois somente assim podemos refletir sobre o impacto nos sistemas (público e privado) mais seletivos e elitistas.

De todo modo, pode-se perceber nesse artigo o que já foi observado em outros estudos: um rendimento maior de estudantes ingressos pelas ações afirmativas em determinados cursos, só que, infelizmente, não dá para comparar com os dados de outras instituições, já que a forma de avaliação não é clara para se verificar que há um percentual acima de 80\% dos cursos a favor dos bolsistas do ProUni. E havendo essa aprovação e um rendimento no mesmo percentual, assim como um baixo percentual de evasão (12,9\%), pergunto: Onde aparecem as dificuldades para esses alunos no sistema privado? Estariam estes estudantes, oriundos de famílias de baixa renda (entre um salário mínimo e meio e três salários mínimos), inclusos em ambiente deveras distinto de sua renda familiar e trajetória sociocultural?

Se o ProUni pode ser inserido como o único programa governamental de ações afirmativas de ingresso no ensino superior, a própria expressão ação afirmativa, nos últimos anos, deve ser vista no Brasil com sentido que cada vez mais se alarga, a partir de sujeitos que estão inseridos no contexto de reivindicações de movimentos sociais. A tendência indica a perspectiva do ativismo social com discursos acadêmicos sobre o que seja a produção do conhecimento.

E isso pode ser verificado no artigo de Marques, Franco e Schlindwein (2011). A reflexão é sobre "a universidade pública gratuita, com qualidade de ensino gratuita, ainda como um privilégio de ingresso de estudantes dos estratos altos e médios da população brasileira". O foco são os movimentos sociais no campo e a presença de estudantes assentados da reforma agrária em cursos superiores (Pedagogia, Geografia e Agronomia). Visto como resultado de pressão, o artigo analisa o curso de Agronomia da Universidade Federal de São Carlos (UFSCar) como uma ação afirmativa e reivindicação de organizações do movimento social, criticando o referencial conceitual analítico e cartesiano, apontando a necessidade de uma visão sistêmica na agroecologia e verificando que se "despreza os saberes historicamente acumulados pelos agricultores". A metodologia e o modelo de gestão do curso são argumentados numa perspectiva construtivista amparada em Pierre Bourdieu e Passeron (1975).

E é curiosa a recorrência desses dois autores em vários estudos no Brasil sobre seletividade social, acesso à universidade pública e a manutenção das desigualdades sociais. Daí, penso que é necessário refletir sobre os seus argumentos acerca de políticas particularistas, vistas nos últimos anos como ações afirmativas, pois um artigo de Bourdieu e Wacquant (1998) foi bastante incisivo, já que objetivavam verificar o imperialismo 
cultural, representado aqui pelos Estados Unidos, e a sua universalização de particularismos no Brasil. Uma das afirmações dos autores franceses é que a "sociodiceia racial (ou racista)" que se mundializou nos últimos anos é uma confirmação exemplar do "império e da influência simbólicos que os Estados Unidos exercem sobre toda espécie de produção erudita e, sobretudo, semierudita, em particular, através do poder de consagração que esse país detém e dos benefícios materiais e simbólicos que a adesão mais ou menos assumida ou vergonhosa ao modelo norte-americano proporciona aos pesquisadores dos países dominados", e que uma violência simbólica não seria exercida a não ser pela cumplicidade ("extorquida") e a colaboração daqueles que a sofrem (Bourdieu; Wacquant, 1998).

Como já argumentei (Santos, 2002), seria necessário Bourdieu e Wacquant pensarem que, no contexto local, as representações sobre política, identidade e cultura, no que tange a uma "racialização", não se manifestam como meras tábulas rasas de artimanhas imperialistas e do seu modelo racial hegemônico. As ressignificações sobre as relações raciais e a adoção de políticas públicas ocorrem principalmente numa disputa pelo "campo" do poder, configurado por projetos, em determinado contexto, a que nem os ativistas nem os intelectuais conseguiram escapar, como pode ser observado nos acalorados debates, nos últimos dez anos, sobre as ações afirmativas no ingresso ao ensino superior. Desse modo, é de se estranhar os usos e abusos que se faz dos argumentos de Bourdieu para amparar a defesa das ações afirmativas para grupos e populações marginalizadas no ensino superior.

O alargamento da definição das ações afirmativas pode também ser observado no artigo de Agostinho e Brega Filho (2011). Com a intenção de inserir-se no campo do direito, critica o conservadorismo histórico e quer buscar "a ratio juris das ações afirmativas". A proposta é amparada na análise filosófica das desigualdades a partir da matriz da "democracia radical" segundo a politicóloga Chantal Mouffe, uma crítica do universalismo, já que este provoca "mecanismos de exclusão". Desse modo, vê como ações afirmativas a Lei Maria da Penha, o Estatuto do Idoso, os percentuais para portadores de deficiência em cargos e empregos públicos, a desobrigação de atividades para os adeptos da Igreja Adventista do Sétimo Dia. É uma perspectiva vista como isonomia.

Mas se Bourdieu e Wacquant apontavam um modelo americano, visto como um imperialismo cultural, outros argumentos contrários à adoção de ações afirmativas foram publicados - é o caso do artigo de Pereira e Zientarski na Rbep $\mathrm{n}^{\circ} 232$. As autoras questionam as ações afirmativas no ensino superior e evocam a condição "socioeconômica das classes excluídas"; a "atenção principal recai sobre a situação da escola básica e seus resultados", e afirmam que, nos países do Terceiro Mundo, houve uma cópia de "soluções dos países dominantes do capitalismo central, sem considerar as diferenças estruturais e culturais entre o país que inspirou essas políticas na América do Norte e os países da América Latina". Deveriam problematizar a razão de não haver reserva de vagas, e respectivos percentuais, no sistema de ingresso nos Estados Unidos, 
assim como perceber que no Brasil os modelos de ingressos adotados nas universidades são diferenciados, mesmo havendo uma predominância do sistema de cotas.

No contexto da adoção dessas políticas, faria sentido o uso, pelas autoras, da perspectiva de "cultura transplantada" de Portugal para o Brasil, utilizada por Nelson Werneck Sodré, e relacionar a "exploração do trabalho escravo" com a situação de desigualdades regionais ainda hoje no País?

A perspectiva de que a desigualdade racial é um epifenômeno da desigualdade de classe não é recente. Aparece com bastante ênfase entre os anos 30 e 50 em estudos desenvolvidos por pesquisadores brasileiros e estrangeiros (norte-americanos e também franceses). Não é à toa que se tornou parte também das percepções do senso comum. Somente durante os anos 70 e 80 pesquisas de Carlos Hasenbalg e Nelson do Valle Silva apontariam para a coexistência entre racismo e crescimento industrial capitalista. Racismo e discriminação passavam a ser argumentados pelos novos significados e funções na estrutura social. E o desafio analítico passou a ser explicar as desigualdades raciais (Castro; Barreto, 1998).

O que surpreende no artigo de Pereira e Zientarski (2011, p. 506) é a afirmação sem nenhum amparo empírico:

A política de cotas, ao contrário, se faz demagógica ao permitir que parte dos negros e dos demais excluídos sociais entrem nas universidades, mas, devido a toda uma conjunção de fatores, não se formem, ou, formados, fiquem alijados do mercado de trabalho, salvo raríssimas exceções.

Assim posto, torna-se poeira ao vento. Dados produzidos sobre desempenho e reprovação em universidades que adotaram políticas particularistas demonstram justamente o contrário.

Vejamos o caso da Universidade Federal da Bahia, observando o desempenho de estudantes cotistas e não cotistas, comparando os coeficientes de rendimento obtidos no segundo (2005.2) e no nono semestres (2009.1) do curso e a situação de ambos os grupos com relação à reprovação por falta nos respectivos cursos. Trata-se aqui da análise do primeiro contingente de estudantes que ingressou na UFBA a partir da implantação da política de reserva de vagas em 2005, cuja maior proporção (85\% da reserva de $43 \%$ para estudantes oriundos do sistema público) é destinada a estudantes autodeclarados negros.

As informações indicam que a maioria deles já cumpriu a maior parte dos créditos das disciplinas. E a despeito das expectativas pessimistas com relação ao desempenho de estudantes que ingressaram na Universidade pelo novo sistema, inclusive em razão da sua origem na escola pública, os resultados obtidos pelos estudantes cotistas ao longo da sua trajetória no curso são animadores. A observação dos coeficientes de rendimento nos dois momentos analisados - o segundo e o nono semestres - evidencia um aumento significativo no contingente de estudantes cotistas com faixa de rendimento mais elevada - entre 7,0 e 10,0 pontos - ao longo do curso. 


\section{O rendimento dos cotistas e dos não cotistas}

Em 71,4\% dos cursos de maior concorrência na área de Matemática, Ciências Físicas e Tecnologia, ocorreu uma elevação no contingente de estudantes que atingiram média 7,0 ou mais elevada, ao longo dos nove semestres, tanto entre cotistas quanto entre os não cotistas. Assim, em ambos os contingentes isso não se verificou em apenas dois dos sete cursos tomados para análise. Para os cotistas isso ocorreu nos cursos de Engenharia Sanitária e Engenharia Civil, enquanto que entre os não cotistas houve uma redução do contingente de estudantes que atingiram média 7,0 nos cursos de Engenharia Elétrica e Engenharia Sanitária, como demonstra a Tabela 2.

Chama a atenção o significativo aumento do contingente de cotistas com média elevada no curso de Engenharia Elétrica, ao mesmo tempo em que há uma redução do contingente de não cotistas com médias nesse patamar. Dados como esse apontam para a necessidade de pesquisas que permitam conhecer as histórias desses sujeitos, no sentido de compreender melhor em que condições e a partir de que referências constroem as possibilidades para tal desempenho.

Tabela 2 - Distribuição Percentual de Estudantes Cotistas e de Não Cotistas Ingressos em 2005.1 com Coeficiente de Rendimento na Faixa entre 7,0 e 10,0 Pontos, nos Cursos de Maior Concorrência nas Áreas de Matemática, Ciências Físicas e Tecnologia

\begin{tabular}{|c|c|c|c|c|}
\hline \multirow[b]{2}{*}{ Curso } & \multicolumn{2}{|c|}{ Cotista } & \multicolumn{2}{|c|}{ Não Cotista } \\
\hline & $\begin{array}{c}2^{\circ} \\
\text { Semestre }\end{array}$ & $\begin{array}{c}9^{\circ} \\
\text { Semestre }\end{array}$ & $\begin{array}{c}2^{o} \\
\text { Semestre }\end{array}$ & $\begin{array}{c}9^{\circ} \\
\text { Semestre }\end{array}$ \\
\hline Ciências da Computação & 22,0 & 44,5 & 23,0 & 30,8 \\
\hline Engenharia Civil & 59,0 & 47,1 & 48,0 & 68,0 \\
\hline Engenharia Elétrica & 56,0 & 77,8 & 75,0 & 57,2 \\
\hline Engenharia de Minas & 9,0 & 18,2 & 6,4 & 14,3 \\
\hline Engenharia Sanitária & 64,0 & 30,0 & 86,0 & 52,2 \\
\hline Geofísica & 14,3 & 28,0 & 10,0 & 55,6 \\
\hline Química & 16,7 & 33,4 & 11,8 & 25,8 \\
\hline
\end{tabular}

Fonte: Serviço de Seleção e Orientação da Universidade Federal da Bahia (SSOA/UFBA), 2011.

Na área de Ciências Biológicas e Profissões da Saúde, se tomarmos os seis cursos considerados de mais elevado prestígio e/ou de mais significativa concorrência, vamos observar o grande contingente de estudantes cujos coeficientes de rendimento se situam na faixa de médias entre 7,0 e 10,0 pontos. Entre os estudantes cotistas, em praticamente todos os cursos, excetuando-se o curso de Enfermagem, em que o percentual permanece o mesmo do segundo semestre, houve significativo aumento no contingente daqueles cujas médias atingiram esses patamares no nono semestre. O curso de Odontologia é o que 
melhor expressa esse crescimento. Entre os cotistas, no segundo semestre, essa faixa de médias era atingida por apenas 15\% do grupo; no nono semestre chega a 53,8\%. Entre os não cotistas, embora também se observe uma tendência à melhoria do desempenho, houve uma redução acentuada nos níveis de rendimento dos estudantes do curso de Farmácia, de 70,6\% no primeiro momento para 31,2\% no nono semestre (Tabela 3).

Tabela 3 - Distribuição Percentual de Estudantes Cotistas e de Não Cotistas Ingressos em 2005.1 com Coeficiente de Rendimento na Faixa entre 7,0 e 10,0 Pontos nos Cursos de Maior Concorrência na Área de Ciências Biológicas e Profissões da Saúde

\begin{tabular}{|l|c|c|c|c|}
\multirow{2}{*}{\multicolumn{1}{c|}{ Curso }} & \multicolumn{2}{c|}{ Cotista } & \multicolumn{2}{c|}{ Não Cotista } \\
\cline { 2 - 5 } & \multicolumn{1}{c}{$\begin{array}{c}\mathbf{2}^{\mathbf{0}} \\
\text { Semestre }\end{array}$} & $\begin{array}{c}\mathbf{9}^{\mathbf{0}} \\
\text { Semestre }\end{array}$ & $\begin{array}{c}\mathbf{2}^{\mathbf{0}} \\
\text { Semestre }\end{array}$ & $\begin{array}{c}\mathbf{9}^{\mathbf{0}} \\
\text { Semestre }\end{array}$ \\
\hline Fonoaudiologia & 84,0 & 92,3 & 83,0 & 83,4 \\
\hline Enfermagem & 75,0 & 75,0 & 50,0 & 64,3 \\
\hline Medicina & 60,0 & 86,7 & 65,0 & 91,7 \\
\hline Odontologia & 15,0 & 53,8 & 50,0 & 81,2 \\
\hline Farmácia & 15,4 & 38,5 & 70,6 & 31,2 \\
\hline Medicina Veterinária & 7,7 & 30,8 & 18,2 & 35,0 \\
\hline
\end{tabular}

Fonte: Serviço de Seleção e Orientação da Universidade Federal da Bahia (SSOA/UFBA), 2011.

Os quatro cursos de maior concorrência e prestígio da área de Filosofia e Ciências Humanas revelam que a posição dos dois grupos é relativamente similar com relação à sua participação na faixa mais elevada de rendimento acadêmico. Em dois cursos dessa área, entre os cotistas e não cotistas, cresceu a parcela de estudantes na faixa mais elevada de rendimentos; os dois grupos mantiveram a posição inicial em um dos cursos e também reduziram a parcela de estudantes com esse nível de rendimento. Assim, no curso de Comunicação, o rendimento do grupo de cotistas teve decréscimo entre o segundo e o nono semestres, embora se mantenha entre eles a maior proporção de estudantes com médias elevadas.

No curso de Direito, não foi alterada a posição dos cotistas entre o segundo e o nono semestres, mas a vantagem é dos não cotistas, que aumentaram em pouco mais de $1 \%$ a parcela de estudantes com notas na faixa de médias mais elevadas. No curso de Psicologia, os cotistas ampliaram, entre o segundo e o nono semestres, a parcela de estudantes com médias elevadas em mais de dez pontos percentuais, enquanto os não cotistas experimentaram um decréscimo de quase $5 \%$. No curso de Administração, os dois grupos experimentaram melhora expressiva no seu rendimento, embora a melhor situação seja dos cotistas, que aumentaram em quase trinta pontos percentuais a parcela de estudantes com notas elevadas. 
Tabela 4 - Distribuição Percentual de Estudantes Cotistas e de Não Cotistas Ingressos em 2005.1 com Coeficiente de Rendimento na Faixa entre 7,6 e 10,0 Pontos nos Cursos de Maior Concorrência na Área de Filosofia e Ciências Humanas

\begin{tabular}{|c|c|c|c|c|}
\hline \multirow{2}{*}{ Curso } & \multicolumn{2}{|c|}{ Cotista } & \multicolumn{2}{|c|}{ Não cotista } \\
\hline & $2^{\circ}$ Semestre & $9^{\circ}$ Semestre & $2^{\circ}$ Semestre & $9^{\circ}$ Semestre \\
\hline Comunicação & 100,0 & 71,4 & 62,5 & 62,0 \\
\hline Direito & 62,0 & 62,0 & 78,0 & 79,4 \\
\hline Psicologia & 77,0 & 88,9 & 100,0 & 95,2 \\
\hline Administração & 47,0 & 76,5 & 68,0 & 77,3 \\
\hline
\end{tabular}

Fonte: Serviço de Seleção e Orientação da Universidade Federal da Bahia (SSOA/UFBA), 2011.

\section{Estudantes cotistas e não cotistas reprovados por falta}

Como visto no desempenho dos cotistas com relação ao rendimento no curso, a reprovação por falta também ocorreu em menor proporção. Os estudantes cotistas estiveram menos sujeitos à reprovação por falta em 63,6\% dos cursos.

Na Área de Matemática, Ciências Físicas e Tecnologia, ocorreram reprovações por falta em menor proporção entre os cotistas que entre os não cotistas em 55\% dos cursos. Em Engenharia Elétrica, enquanto os não cotistas apresentam quase 3\% de estudantes reprovados por esse critério, entre os cotistas a reprovação é próxima de zero, como mostra a Tabela 5. No curso de Engenharia Florestal, a proporção de não cotistas reprovados por falta foi quase quinze pontos mais elevada que entre os cotistas. A maior distância entre cotistas e não cotistas com relação a esse tipo de reprovação está no curso de Física "noturno". Enquanto entre os cotistas a reprovação por falta esteve em torno de 13\%, entre os não cotistas o percentual se eleva para 33,8\%, portanto, uma distância de 20 pontos percentuais. Esse dado chama a atenção justamente por se tratar de um curso noturno.

Em 54,5\% dos cursos da Área de Ciências Biológicas e Profissões da Saúde os cotistas apresentaram uma situação mais favorável que os não cotistas. Chama a atenção a distância entre os dois contingentes no curso de Zootecnia, como se pode constatar na Tabela 5. Também no curso de Enfermagem observa-se uma expressiva distância entre os dois contingentes: enquanto a reprovação entre os não cotistas se eleva a mais de oito pontos percentuais, entre os cotistas não alcança um ponto. Em Nutrição, mesmo que os índices de reprovação não sejam elevados em ambos os grupos, os não cotistas reprovados por falta são o dobro dos cotistas. 
Tabela 5 - Distribuição Percentual de Estudantes Cotistas e de Não Cotistas Ingressos em 2005 na Área I Reprovados por Falta - UFBA-Semestre 2009.1

\begin{tabular}{|l|c|c|}
\hline \multicolumn{1}{|c|}{ Curso } & Cotistas & Não Cotistas \\
\hline Arquitetura & 9,03 & 5,41 \\
\hline Engenharia Civil & 7,32 & 3,59 \\
\hline Engenharia de Minas & 10,31 & 17,64 \\
\hline Engenharia Elétrica & 0,19 & 2,71 \\
\hline Engenharia Mecânica & 3,05 & 2,03 \\
\hline Engenharia Química & 7,06 & 3,99 \\
\hline Engenharia Sanitária & 6,74 & 7,38 \\
\hline Engenharia Florestal & 10,47 & 25,13 \\
\hline Engenharia de Pesca & 13,13 & 13,13 \\
\hline Física & 10,47 & 21,82 \\
\hline Geografia & 16,86 & 16,00 \\
\hline Geologia & 18,18 & 15,72 \\
\hline Matemática & 12,01 & 27,27 \\
\hline Ciência da Computação & 8,14 & 8,47 \\
\hline Química & 8,76 & 21,90 \\
\hline Estatística & 17,01 & 21,70 \\
\hline Geofísica & 15,82 & 5,08 \\
\hline Oceanografia & 14,89 & 16,18 \\
\hline Física noturno & 13,83 & 30,84 \\
\hline
\end{tabular}

Fonte: Serviço de Seleção e Orientação da Universidade Federal da Bahia (SSOA/UFBA), 2011.

Tabela 6 - Distribuição Percentual de Estudantes Cotistas e de Não Cotistas Ingressos em 2005 na Área II Reprovados por Falta - UFBA-Semestre 2009.1

\begin{tabular}{|l|c|c|}
\hline \multicolumn{1}{|c|}{ Curso } & Cotistas & Não Cotistas \\
\hline Agronomia & 9,22 & 6,83 \\
\hline Biologia & 3,09 & 6,70 \\
\hline Enfermagem & 0,85 & 8,12 \\
\hline Farmácia & 2,93 & 2,48 \\
\hline Medicina & 1,19 & 0,17 \\
\hline Medicina Veterinária & 3,28 & 3,28 \\
\hline Nutrição & 2,50 & 5,10 \\
\hline Odontologia & 1,07 & 1,60 \\
\hline Ciências Naturais & 9,96 & 11,60 \\
\hline Fonoaudiologia & 1,36 & 0,85 \\
\hline Zootecnia & 5,56 & 33,33 \\
\hline
\end{tabular}

Fonte: Serviço de Seleção e Orientação da Universidade Federal da Bahia (SSOA/UFBA), 2011. 
Na Área de Filosofia e Ciências Humanas, os cotistas obtiveram desempenho melhor que os não cotistas em $80 \%$ dos cursos. E nos demais 20\%, em que os não cotistas obtiveram desempenho melhor, a distância entre os dois grupos é pequena, sempre abaixo dos 2,5 pontos, como no curso de Letras Vernáculas, a maior distância em favor dos não cotistas. A vantagem dos cotistas se evidencia também na expressão das distâncias para os não cotistas. No curso de Museologia, os não cotistas foram reprovados quase quatro vezes mais do que os cotistas. Em Educação Física, a reprovação entre os não cotistas é praticamente o dobro dos cotistas.

Tabela 7 - Distribuição Percentual de Estudantes Cotistas e de Não Cotistas Ingressos em 2005 na Área III Reprovados por Falta - UFBA-Semestre 2009.1

\begin{tabular}{|l|r|r|}
\hline \multicolumn{1}{c}{ Curso } & Cotistas & Não Cotistas \\
\hline Biblioteconomia & 9,9 & 8,6 \\
\hline Ciências Contábeis & 10,4 & 14,0 \\
\hline Economia & 11,6 & 14,0 \\
\hline Ciências Sociais & 12,5 & 13,7 \\
\hline Comunicação & 9,5 & 11,2 \\
\hline Direito & 3,0 & 1,5 \\
\hline Filosofia & 17,0 & 16,2 \\
\hline História & 7,6 & 9,3 \\
\hline Museologia & 5,5 & 18,2 \\
\hline Pedagogia & 5,1 & 7,5 \\
\hline Psicologia & 1,7 & 1,3 \\
\hline Secretariado & 2,2 & 4,0 \\
\hline Educação Física & 9,7 & 19,3 \\
\hline Administração & 3,9 & 6,1 \\
\hline Arquivologia & 9,0 & 11,2 \\
\hline Letras Vernáculas & 7,2 & 5,4 \\
\hline Letras Vernáculas c/Língua Estrangeira & 6,4 & 7,9 \\
\hline Letras - Língua Estrangeira & 11,4 & 10,8 \\
\hline
\end{tabular}

Fonte: Serviço de Seleção e Orientação da Universidade Federal da Bahia (SSOA/UFBA), 2011.

Outros estudos já foram produzidos sobre o desempenho, como na Universidade Estadual de Mato Grosso do Sul (Cordeiro, 2007), na Estadual do Norte Fluminense (Brandão; Matta, 2007), na do Estado de Mato Grosso (Vieira, 2007) ou mesmo na UFBA (Santos; Queiroz, 2005-2006; Queiroz; Santos, 2007), assim como a simulação de adoção do sistema de cotas na Universidade Federal de Santa Catarina (Tragtenberg et al., 2006). Um artigo publicado na Rbep por Velloso e Cardoso (2011) testa justamente hipóteses contrárias ao sistema de cotas que surgiram no debate, como menor desempenho dos candidatos oriundos desse sistema, maior evasão, assim como as reivindicações de aumento do número de vagas e prioridade nas políticas universalistas para um aumento de negros nas universidades. E vejamos a conclusão: 
[...] as simulações efetuadas na UnB e noutra universidade federal, se puderem ser generalizadas para o cenário da educação superior no País, parecem depor a favor das cotas e, ao mesmo tempo, ajudam a colocá-las em perspectiva. [...] Nesse contexto, não espanta que uma radical duplicação de vagas - ainda que só hipotética, porque inviável em curto ou médio prazo - não corresponda a uma igualmente drástica ampliação das probabilidades de ingresso de negros na universidade (Velloso; Cardoso, 2011, p. 240).

Dois outros artigos publicados na $R b e p$ tratam das políticas adotadas em universidades federais. Doebber e Grisa (2011) analisam a implementação e o desenvolvimento do Programa de Ações Afirmativas da Universidade Federal do Rio Grande do Sul (UFRGS) - trata-se da defesa de políticas racializadas no ensino superior. E a UFRGS adotou 30\% para estudantes oriundos das escolas públicas, sendo 50\% autodeclarados negros. As tensões no Conselho Universitário envolviam a adoção ou não do critério racial, um fato semelhante às inúmeras universidades que adotaram cotas. E é pertinente a observação: "quando se quer transformar a raça em balizador de uma política institucional, aparecem argumentos e atitudes de várias ordens que mostram como é demagógica essa aceitabilidade da existência de desigualdades raciais" (Doebber; Grisa, 2011, p. 585). O não preenchimento das vagas reservadas aos negros aparece na UFRGS, dado que já se apresentava em outras instituições, como a Universidade Federal do Paraná e a Universidade Federal de Santa Catarina. Por isso, penso que é necessário utilizar a comparação dos variados sistemas existentes, para verificar se isso é resultado dos critérios adotados no uso do ponto de corte.

Um dos focos das críticas à adoção das ações afirmativas no ensino superior tem sido a política de permanência de estudantes pobres que ingressaram por esse novo sistema, mas cuja origem social revelaria a dificuldade em desenvolver a contento os seus cursos. Sousa e Portes (2011) analisaram documentos de 59 universidades, de acordo com a lista das Instituições Federais de Ensino Superior (Ifes) disponibilizada no site da Associação Nacional dos Dirigentes das Instituições Federais de Ensino Superior (Andifes).

O objetivo foi "verificar apenas nas resoluções das universidades que adotaram as políticas/ações afirmativas as diferentes propostas e o trato dado às questões relacionadas à permanência/assistência daqueles que pudessem se beneficiar das políticas de acesso implementadas". Elaboraram um quadro com as universidades que adotaram as ações afirmativas, e no "tipo de ação" aparece a expressão classificatória "reserva sociorracial". Acho que é necessário problematizar o uso dessas categorias explicativas, como o uso de cota social que já se propaga inclusive na mídia. O termo "social" passou a indicar origem escolar, e, por conseguinte, aparece uma classificação que aponta para "reserva social" e "reserva racial" ou "bônus social" ou "bônus racial". O que justificaria essa classificação é a visão de que há "aspectos sociais" (Sousa; Portes, 2011, p. 530) na origem escolar e também para os portadores de necessidades especiais.

Estamos diante de uma classificação binária em que os termos funcionam muito mais como pares de opostos. Pergunto se isso 
não seguiria o discurso de "inclusão social" que aparece em alguns documentos e discursos na sociedade brasileira, onde o termo racial aparece sobremaneira como um epifenômeno de classe, e, assim, uma inclusão racial estaria subsumida a uma política voltada para os pobres. Cabe notar também o argumento dos autores quando apontam para a adoção dessas políticas como uma "política de custo zero", posto que a permanência não aparece nas resoluções da grande maioria das universidades.

Três outros artigos fecham a produção sobre as ações afirmativas publicada na Rbep. Rosistolato (2011) reflete sobre as metodologias de ensino de ciências em um pré-vestibular comunitário, trazendo depoimentos de estudantes, na perspectiva de verificar os sentidos da educação escolar entre estudantes de camadas populares em Petrópolis. É interessante observar essas experiências que se espraiam pelo Brasil, desde os anos 90, e apontam para processos educacionais que se desenvolveram sem relação direta com a legislação educacional brasileira, além de se constituírem no que o autor aponta como "construção de redes de solidariedade entre professores, ex-estudantes e familiares", mesmo que, no início do atual século, cursinhos desse perfil tenham tido apoio pontual de órgãos oficiais.

Direcionando a discussão para a educação indígena, Freitas (2011) aponta o papel do Instituto Insikiran de Formação Superior Indígena na formação de professores indígenas em nível superior e, principalmente, o apoio às atividades de educação de organizações e escolas das comunidades. O Núcleo Insikiran foi criado em 2001 na Universidade Federal de Roraima, sendo a primeira experiência numa instituição pública de ensino superior, por meio de um curso de Licenciatura Intercultural (2002), que recebe egressos do magistério indígena e os que estão atuando nas escolas indígenas.

Essa experiência inscreve-se no apoio e fomento de instituições nacionais e estrangeiras, a exemplo da Coordenação de Aperfeiçoamento de Pessoal de Nível Superior (Capes) e da Fundação Ford. Uma característica pontual é a discussão curricular chamada "político-pedagógica", vista como um desafio entre os saberes indígenas e os institucionalizados na academia. Como já observado, a permanência no curso constitui-se um problema intrínseco na inserção de populações excluídas até então do ensino superior. Um desdobramento dessa pesquisa poderia ser a inserção do curso na estrutura formal da instituição universitária, as dificuldades, tensões e disputas no processo de institucionalização, inclusive entre os próprios indígenas. E, como argumenta (Bruno, 2011), entre os próprios índios não há consenso acerca da importância da educação diferenciada, de como devem se organizar ou do lugar que devem assumir na formação das novas gerações no interior de um mesmo grupo ou aldeia. E vale salientar que até o início do século havia entidades do movimento negro brasileiro que também discordavam da adoção de cotas nas universidades. A perspectiva era bastante próxima de tendências que marcavam as esquerdas no Brasil: a razão das desigualdades estava subsumida no epifenômeno de classe. 


\section{Considerações finais}

O que foi aqui apontado é uma tentativa de demonstrar que já se constituiu uma produção acadêmica sobre a adoção das ações afirmativas em universidades brasileiras. E não hesitaria em afirmar que se trata de reflexões a posteriori, ou seja, a partir da institucionalização das ações afirmativas, busca-se utilizar metodologias e aportes teóricos na explicação dessa política. Uma significativa diferença quando se observa o debate caloroso manifesto em anos anteriores e publicado na mídia, e até nos abaixo-assinados de pesquisadores e professores das nossas universidades. A polaridade "opinativa" e passional parece dar lugar à lógica argumentativa e análise dos dados. Por certo, o número de artigos e livros publicados e de dissertações e teses defendidas ainda não dão conta da diversidade na adoção das cotas pelas universidades. Poucas instituições divulgaram seus dados ou foram objeto de análise, porém o crescimento e a importância dessa produção podem ser notados no espaço que uma revista especializada e consolidada como a Rbep a ela dedicou.

\section{Referências bibliográficas}

ADVIR. Cotas: um debate inconcluso. Pablo Gentili (Ed.). Rio de Janeiro, n. 19, set. 2005.

AGOSTINHO, Luis O. V.; BREGA FILHO, Vladimir. Por um olhar democrático às ações afirmativas. Revista Brasileira de Estudos Pedagógicos, Brasília, v. 92, n. 232, p. 455-476, set./dez. 2011.

AZEVEDO, Célia Maria M. de. Abolicionismo e memórias das relações raciais. Estudos Afro-Asiáticos, Rio de Janeiro, n. 26, p. 5-20, set. 1994.

BOURDIEU, Pierre F.; PASSERON, Jean C. A reprodução: elementos para uma teoria do sistema de ensino. Rio de Janeiro: Liv. Francisco Alves, 1975.

; WACQUANT, Löic. Sobre as artimanhas da razão imperialista.

In: NOGUEIRA, M. A.; CATANI, A. (Org.). Escritos de educação. Petrópolis: Vozes, 1998. p. 17-32.

BRANDÃO, André A. (Org.). Cotas raciais no Brasil: a primeira avaliação. Rio de Janeiro: DP\&A, 2007.

; MATTA, Ludmila G. Avaliação da política de reserva de vagas na Universidade Estadual do Norte Fluminense: estudo dos alunos que ingressaram em 2003. In: . (Org.). Cotas raciais no Brasil: a primeira avaliação. Rio de Janeiro: DP\&A, 2007. p. 48-80. 
BRUNO, Lúcia. Gestão da educação escolar indígena diferenciada: contradições, limites e possibilidades. Revista Brasileira de Estudos Pedagógicos, Brasília, v. 92, n. 232, p. 639-662, set./dez. 2011.

CARVALHO, José J. Inclusão étnica e racial no Brasil. São Paulo: Attar, 2006.

CASTRO, Nadya A.; BARRETO, Vanda S. (Org.). Trabalho e desigualdades racias: negros e brancos no mercado de trabalho em Salvador. São Paulo: Annablume/A Cor da Bahia, 1998.

CORDEIRO, Maria José de J. Três anos de efetiva presença de negros e indígenas cotistas nas salas de aula da UEMS: primeiras análises. In: BRANDÃO, André A. (Org.). Cotas raciais no Brasil: a primeira avaliação. Rio de Janeiro: DP\&A, 2007. p. 81-114.

DOEBBER, Michele B.; GRISA, Gregório D. Ações afirmativas: o critério racial e a experiência da Universidade Federal do Rio Grande do Sul. Revista Brasileira de Estudos Pedagógicos, Brasília, v. 92, n. 232, p. 577-598, set./dez. 2011.

FERRI, Cássia et al. Políticas inclusivas no ensino superior: análise do acesso, permanência e aprendizagem dos acadêmicos participantes do ProUni na Universidade do Vale do Itajaí, no período 2006-2007. Revista Brasileira de Estudos Pedagógicos, Brasília, v. 91, n. 228, p. 367-389, maio/ago. 2010.

FREITAS, Marcos Antonio B. de. O Instituto Insikiran da Universidade Federal de Roraima: trajetória das políticas para a educação superior indígena. Revista Brasileira de Estudos Pedagógicos, Brasília, v. 92, n. 232, p. 599-615, set./dez. 2011.

GUIMARÃES, Antonio Sérgio A. Políticas públicas para a ascensão dos negros no Brasil: argumentando pela ação afirmativa. Afro-Ásia, Salvador, n. 18, p. 235-61, 1996.

HASENBALG, Carlos. Discriminação e desigualdades raciais no Brasil. Rio de Janeiro: Graal, 1979.

HELLWIG, David. J. African-American reflections on Brazil's racial paradise. Philadelphia: Temple University Press, 1992.

MARQUES, Waldemar; FRANCO, Fernando S.; SCHLINDWEIN, Marcelo N. Universidade e movimentos sociais no Brasil: uma experiência de ação afirmativa. Revista Brasileira de Estudos Pedagógicos, Brasília, v. 92, n. 232, p. 557-76, set./dez. 2011. 
MOUFFE, Chantal (Ed.) Dimensions of Radical Democracy: Pluralism, Citizenship, Community. London - New York: Verso, 1992.

PEREIRA, Sueli M.; ZIENTARSKI, Clarice. Políticas de ações afirmativas e pobreza no Brasil. Revista Brasileira de Estudos Pedagógicos, Brasília, v. 92, n. 232, p. 493-515, set./dez. 2011.

QUEIROZ, Delcele M.; SANTOS, Jocélio T. dos. Sistema de cotas: um debate. Dos dados à manutenção de privilégios e de poder. Educação \& Sociedade, Campinas-SP, v. 27, n. 96, p. 717-737, out. 2006.

; S_ Sistema de cotas e desempenho de estudantes nos cursos da UFBA. In: BRANDÃO, André A. Cotas raciais no Brasil: a primeira avaliação. Rio de Janeiro: DP\&A, 2007. p. 115-135.

ROSISTOLATO, Rodrigo Pereira da R. Juventudes populares em um pré-vestibular: a construção coletiva de expectativas e campos de possibilidades educacionais. Revista Brasileira de Estudos Pedagógicos, Brasília, v. 92, n. 232, p. 616-638, set./dez. 2011.

SANTOS, Jocélio T. dos. De armadilhas, convicções e dissensões: as relações raciais como efeito orloff. Estudos Afro-Asiáticos, Rio de Janeiro, v. 24, n. 1, p. 167-88, 2002.

. O poder da cultura e a cultura no poder: a disputa simbólica da herança cultural negra no Brasil. Salvador: Ed. Ufba, 2005.

; QUEIROZ, Delcele M. Vestibular com cotas: análise em uma instituição pública federal. Revista USP, São Paulo, n. 68, p. 58-75, dez./fev. 2005-2006.

SILVA, Nelson do V. Cor e processo de realização socioeconômica. In: SILVA et al.; L. A. Machado da (Org.). Movimentos sociais urbanos, minorias étnicas e outros estudos. Brasília: Anpocs. p. 198-219. (Ciências Sociais Hoje, 2).

SILVA, Paula Cristina da. Educação pluricultural e antirracista em Salvador: algumas experiências nos anos 80 e 90. In: SANTOS, Jocélio, T. dos (Org.). Educação e os afro-brasileiros: trajetórias, identidades e alternativas. Salvador: Novos Toques/UFBA, 1997. p. 133-152.

SOUSA, Letícia P.; PORTES, Écio A. As propostas de políticas/ações afirmativas das universidades públicas e as políticas/ações de permanência nos ordenamentos legais. Revista Brasileira de Estudos Pedagógicos, Brasília, v. 92, n. 232, p. 516-541, set./dez. 2011. 
TELLES, Edward E. Racismo à brasileira: uma nova perspectiva sociológica. Rio de Janeiro: Relume Dumará/Fundação Ford, 2003.

TRAGTENBERG, Marcelo H. R. et. al. Como aumentar a proporção de estudantes negros na universidade? Cadernos de Pesquisa, São Paulo, v. 36, n. 128, p. 473-495, maio/ago. 2006.

VELLOSO, Jacques; CARDOSO, Claudete B. Um quinquênio de cotas: as chances de ingresso de negros na Universidade de Brasília. Revista Brasileira de Estudos Pedagógicos, Brasília, v. 92, n. 231, p. 221-245, maio/ago. 2011.

VIEIRA, Paulo Alberto dos S. Políticas afirmativas, população negra e ensino superior em Mato Grosso: avaliando as cotas na Unemat. In: BRANDÃO, André A.(Org.). Cotas raciais no Brasil: a primeira avaliação. Rio de Janeiro: DP\&A, 2007. p. 213-238.

WALTERS, Ronald. O princípio da ação afirmativa e o progresso racial nos Estados Unidos. Estudos Afro-Asiáticos, Rio de Janeiro, n. 28, p. 129-140, out. 1995.

Jocélio Teles dos Santos, doutor em Antropologia pela Universidade de São Paulo (USP), é professor associado do Departamento de Antropologia e do Programa de Pós-Graduação em Estudos Étnicos e Africanos da Universidade Federal da Bahia (UFBA) e Bolsista de Produtividade do Conselho Nacional de Desenvolvimento Científico e Tecnológico (CNPq). jocelio@ufba.br 